\title{
Effects of Cold-Press and Soxhlet Extraction Systems on Antioxidant Activity, Total Phenol Contents, Fatty Acids, and Tocopherol Contents of Walnut Kernel Oils
}

\author{
Isam A. Mohamed Ahmed ${ }^{1 *}$, Fahad Y. Al-Juhaimi ${ }^{1}$, Mehmet Musa Özcan ${ }^{2}$, \\ Magdi A. Osman ${ }^{1}$, Mustafa A. Gassem ${ }^{1}$, and Hesham A. A. Salih ${ }^{1}$ \\ ${ }^{1}$ Department of Food Science \& Nutrition, College of Food and Agricultural Sciences, King Saud University, Riyadh-SAUDI ARABIA \\ ${ }^{2}$ Department of Food Engineering, Faculty of Agriculture, University of Selçuk, 42031 Konya, TURKEY
}

\begin{abstract}
In this study, physico-chemical properties, fatty acid composition, and tocopherol contents of several walnut kernel oils obtained through cold-press and Soxhlet extractions were investigated. The acidity, peroxide, and unsaponifiable matter of oil samples extracted in the Soxhlet system were found higher. Total phenol contents of the oils obtained in cold press and Soxhlet extraction systems were $121.9 \mathrm{mg}$ GAE/100g (Kaman-2) and $154.6 \mathrm{mg} \mathrm{GAE} / 100 \mathrm{~g}$ (Büyükoba), and between $135.9 \mathrm{mg}$ GAE/100g (Kaman-2) and $163.8 \mathrm{mg} \mathrm{GAE} / 100 \mathrm{~g}$ (Büyükoba), respectively $(p<0.05)$. In addition, antioxidant activity valuesof walnut oils obtained in cold press and Soxhlet extractions varied between 17.3\% (Kaman-2) and 19.7\% (Kaman-5), and between $18.4 \%$ (Kaman-2) and $23.8 \%$ (Büyükoba), respectively $(p<0.05)$. Linoleic acid contents of the oil samples extracted in cold-press varied between $55.19 \%$ (Kaman-5) and $56.71 \%$ (Kaman-2), while that extracted from Soxhlet extraction system varied between $54.47 \%$ (Kaman-2) and $55.93 \%$ (Büyükoba). $y$-Tocopherol contents of walnut oils extracted in cold press and Soxhlet extraction ranged between $9.41 \mathrm{mg} / 100 \mathrm{~g}$ (Büyükoba) and $10.83 \mathrm{mg} / 100 \mathrm{~g}(\mathrm{Kaman}-2)$, and $8.76 \mathrm{mg} / 100 \mathrm{~g}$ (Kaman-5) and $9.33 \mathrm{mg} / 100 \mathrm{~g}($ Kaman-2), respectively, and were statistically significant $(p<0.05)$.
\end{abstract}

Key words: walnut oil, total phenol, antioxidant activity, fatty acids, tocopherols, GC, HPLC

\section{INTRODUCTION}

Walnut (Juglansregia L.) is considered as one of the oldest fruits cultivated in different parts of the world including Turkey. Most nuts are rich in monounsaturated fatty acids, but walnuts are also high in two polyunsaturated fatty acids (linoleic and $\alpha$-linolenic $)^{1,2)}$. Nuts have special common properties such as high oil content when compared to other oilseed species, and they are part of healthy diets ${ }^{3)}$. Walnut kernel contains about $52-75 \%$ of oil depending on the variety, cultivation and irrigation of walnut trees. Regarding the fatty acid composition, unsaturated fatty acids such as oleic, linoleic, and linolenic acids dominate ${ }^{4-7)}$. Among the tocopherol fraction, the dominant tocopherol is $\gamma$-tocopherol, comprising $88 \%$ of the total tocopherols $^{5,8)}$. Some commonly used methods for oil production include pressing, Soxhlet extraction, and combined pre-pressing and solvent extraction ${ }^{9)}$. Walnut kernel oil obtained by cold-press has higher amount of essential fatty acid and different bioactive compounds than those of some other common vegetable oils, which can serve as apromising alternate edible oil. Cold-pressing does not need both heat and chemical treatments, and hence, it does not destroy the beneficial properties of oils. Because of these properties, the demand for cold-press oils is increasing for natural and safe food products ${ }^{10)}$. Recently, there was an increasing demand to consume cold-pressed plant oils because of better nutritive properties. Cold-pressingis also environment friendly as it does not require much energy ${ }^{11)}$. Although extraction with cold-pressing has been proposed, solvent extraction is the most widely used procedure on an industrial scale. However, limited information is available about qualitative comparison of walnut oils obtained by cold-press and solvent systems. The current study reports the experimental results about walnut oils obtained usingpetroleum ether-assisted Soxhlet extraction and cold pressing. The objective of this study was to determine the effect of cold-press and Soxhlet extraction techniques on physico-chemical characteristics, and fatty acid and to-

*Correspondence to: Isam A. Mohamed Ahmed, Department of Food Science \& Nutrition, College of Food and Agricultural Sciences, King Saud University, Riyadh-SAUDI ARABIA

E-mail: iali@ksu.edu.sa

Accepted October 31, 2018 (received for review July 20, 2018)

Journal of Oleo Science ISSN 1345-8957 print / ISSN 1347-3352 online

http://www.jstage.jst.go.jp/browse/jos/ http://mc.manusriptcentral.com/jjocs 


\section{A. M. Ahmed, F. Y. A.-Juhaimi, M. M. Özcan et al.}

copherol contents of the kernel oils obtained from three walnut varieties.

\section{MATERIAL AND METHODS}

\subsection{Materials}

Walnut fruits (Kaman-2, Kaman-5, and Büyükoba varieties with commercial importance) were collected from 20 selected walnut trees from Kırşehir Province, Turkey, in September 2017. The fruits were air-dried, hulls were removed, and the walnut kernels were homogenized, and stored at $4^{\circ} \mathrm{C}$ for further analyses.

\subsection{Methods}

\subsubsection{Cold-press}

The oil of walnut kernel was obtained by using coldpress extraction process after removing the broken or damaged walnut kernels and other impurities such as stem, and skin as they can have negative effects on the oil quality. Whole kernel was extracted with cold-press (2-6 L/ h capacity) without heat treatment. Once pressed, the oil was allowed to sediment for a week to remove solid impurities. After sedimentation, the oil was filtrated, and purified oil was kept in a hermetically closed colored bottle under nitrogen at $4{ }^{\circ} \mathrm{C}$.

\subsubsection{Soxhlet extraction}

Walnut kernels were ground and extracted for $6 \mathrm{~h}$ using petroleum ether $\left(50^{\circ} \mathrm{C}\right)$ in a Soxhlet extractor followed by evaporation of the solvent under reduced pressure. The extracted oil was kept in sealed glass bottles at $-18^{\circ} \mathrm{C}$ for before further analysis.

\subsubsection{Physico-chemical properties}

Standard $\mathrm{AOAC}^{12)}$ methods were used to determine the acid, peroxide value, density, iodine value, refractive index, and saponifiable and unsaponifiable values of oil samples.

\subsubsection{Sample extraction}

Total phenol content and antioxidant activity analyses of oils were carried out by extraction method as reported by Talhaoui et al. ${ }^{13)}$ with some modifications. Walnut kernels were ground, and $4 \mathrm{~g}$ from each sample was mixed with 20 $\mathrm{mL}$ of methanol followed by 15-min sonicationand 10-min centrifugation at $5000 \mathrm{rpm}$. The extraction was carried out in two cycles and centrifuged supernatants were separated and concentrated at $37^{\circ} \mathrm{C}$ in a rotary evaporator under vacuum. The extracted volume was made up to $25 \mathrm{~mL}$ using methanol.

\subsubsection{Total phenolic content}

Folin-Ciocalteu (FC) reagent methods as reported byYoo et $a l .{ }^{14)}$ was used for evaluating the phenolic contents of the extracts. Folin-Ciocalteu $(1 \mathrm{~mL})$ and extract sample $(0.5$ $\mathrm{mL}$ ) were combined and mixed for 5 min followed by the addition of $10 \mathrm{~mL} \mathrm{Na} \mathrm{CO}_{3}(7.5 \%)$ and making the volume to $25 \mathrm{~mL}$ using distilled water. The samples were mixed well and kept for $1 \mathrm{~h}$, after which the absorbance was measured at $750 \mathrm{~nm}$ in spectrophotometer (Shimadzu, Japan). Gallic acid (GA) was used as standard for making the calibration curve and the results were given as mg GAE/100 g.

2.2.6 Antioxidant activity

Methanolic solution of DPPH(1,1-diphenyl-2-picrylhydrazyl ${ }^{15)}$ was used for assessing the antioxidant activity in oil samples. First, $1 \mathrm{~mL}$ of the extract was mixed with $2 \mathrm{~mL}$ methanolic solution of DPPH followed by vigorous shaking, 30-min incubation at room temperature, and measurement of absorbance values at $517 \mathrm{~nm}$ using a spectrophotometer. 2.2.7 Fatty acid composition

Walnut oil samples were first esterified using the ISO$5509^{16)}$ procedure followed by identifying fatty acid methyl esters through comparison of retention time with those obtained from the samples and standards. The fatty acid methyl esters were injected in a gas chromatography system (Shimadzu GC-2010) equipped with a capillary column(Tecnocroma TR-CN100, $60 \mathrm{~m} \times 0.25 \mathrm{~mm}$, film thickness: $0.20 \mu \mathrm{m}$ ) and a flame-ionization detector(FID). The injection block and detector temperatures were set at $260^{\circ} \mathrm{C}$ and nitrogen at a flow rate of $1.51 \mathrm{~mL} / \mathrm{min}$ was used as the mobile phase. The total flow rate was $80 \mathrm{~mL} / \mathrm{min}$, whereas the split rate was $1 / 40$. The column temperature was set as $120^{\circ} \mathrm{C}$ for 5 min followed by an increment of $4{ }^{\circ} \mathrm{C}$ $/ \mathrm{min}$ until it reached $240^{\circ} \mathrm{C}$ where it was held for $25 \mathrm{~min}$. 2.2.8 Tocopherol content

A $20 \mu \mathrm{L}$ sample (obtained by solubilizing $250 \mathrm{mg}$ of oil in $25 \mathrm{~mL}$ of $n$-heptane) was directly injected to a Diol phase HPLC column $25 \mathrm{~cm} \times 4.6 \mathrm{mmID}$ (Merck, Darmstadt, Germany) at a flow rate of $1.3 \mathrm{~mL} / \mathrm{min}$. The contents of tocopherol in either cold-pressed or Soxhlet extraction oil samples were determined following the method of Spika et $a l .{ }^{17)}$. The HPLC system for tocopherol analysis consisted of Shimadzu-HPLC equipped with a PDA detector and LiChroCART Silica $60(4.6 \times 250 \mathrm{~mm}, 5 \mu$; Merck, Darmstadt, Germany) column. Standard solutions of tocopherols ( $\alpha-$, $\beta$-, $\gamma$-, and $\delta$-tocopherol)were used at $0-100 \mathrm{mg} / \mathrm{L}$ concentrations for comparison and quantification. The mobile phase used was $n$-heptane/tert-butyl methyl ether (99/1, v/ v).

\subsection{Statistical Analyses}

All analytical measurements were carried out in triplicate and a complete randomized split plot block design was used for carrying out the experiment. The obtained data were analyzed using analysis of variance (ANOVA) and performed in JMP version 9.0 (SAS Inst. Inc., Cary, N.C.U.S.A) . The results were expressed as means \pm standard deviation of independent walnut oil samples ${ }^{18)}$. 


\section{RESULTS AND DISCUSSION}

The physicochemical properties, total phenol contents, and antioxidant activities of walnut oils obtained through cold-press and Soxhlet extraction are presented in Table 1. The acidity values of the oil samples obtained from coldpress were between $0.37 \mathrm{mgKOH} / \mathrm{g}$ (Büyükoba) and 0.48 $\mathrm{mg} \mathrm{KOH/g}$ (Kaman-2), while the acid values of walnut oils extracted using the Soxhlet apparatus ranged between 0.45 mg KOH/g (Büyükoba) and $0.54 \mathrm{mg} \mathrm{KOH/g} \mathrm{(Kaman-5).} \mathrm{The}$ higher acid values of walnut kernel oils extracted by Soxhlet extraction could be attributed to the high action of lypolytic enzyme. The peroxide values of walnut oil samples obtained from cold-press were between 1.89 meq $\mathrm{O}_{2} / \mathrm{kg}$ (Büyükoba) and 2.68 meq $\mathrm{O}_{2} / \mathrm{kg}$ (Kaman-5) $(p<0.05)$, while that obtained from Soxhlet apparatus ranged between 2.09 (Büyükoba) and $2.87 \mathrm{meq} \mathrm{O}_{2} / \mathrm{kg}$ (Kaman-5). The walnut oil obtained from the Büyükoba variety extracted from cold-press and Soxhlet apparatus had the lowest peroxide values of 1.89 and 2.09 meq $\mathrm{O}_{2} / \mathrm{kg}$, respectively. However, the increase in the peroxide values of walnut oils extracted by Soxhlet apparatus can be attributed to the solvent used, heat application, and oxygen contact during extraction process. Generally, acidity and peroxide values of walnut oils extracted in the Soxhlet system were higher than those of walnut oils obtained using a cold-press system. The saponification values of walnut oils obtained in cold-press varied between 104.6 (Kaman-2) and 109.9 (Kaman-5), while that extracted from the Soxhlet system were between 103.9 (Kaman-2) and 108.2 (Kaman-5). Also the unsaponification matter values of walnut kernel oils obtained from cold-press varied between $0.41 \%$ (Kaman-5) and $0.48 \%$ (Kaman-2), while that from the Soxhlet system were between $0.87 \%$ (Kaman-2) and $0.93 \%$ (Kaman-5). Increase in the unsaponifiable matter of walnut kernel oils obtained in the Soxhlet apparatus can be attributed to the conversion of more matter into oil from the seeds due to the solvent used. Significant differences were observed among the physicochemical and bioactive properties of walnut oil samples extracted from the cold-press and Soxhlet apparatus. In addition, acidity values of Kaman 2 and Büyükoba and refractive index values of Kaman 2 and Kaman 5 walnut oils obtained through cold-press were found to be statistically similar. Özcan et al. ${ }^{2)}$ determined 3.18-3.53 meq $\mathrm{O}_{2} / \mathrm{kg}$ peroxide value, $0.35-0.56 \%$ acidity, 102.09 114.6 saponification value, and $1.534-1.537$ refractive index in the walnut oils extracted in the Soxhlet system. The total phenol contents of walnut kernel oils obtained from cold-press ranged between $121.9 \mathrm{mg}$ GAE/100g (Kaman-2) and $154.6 \mathrm{mg}$ GAE/100g (Büyükoba), while that extracted through Soxhlet extraction ranged between $135.9 \mathrm{mg}$ GAE/100g (Kaman-2) and $163.8 \mathrm{mg} \mathrm{GAE} / 100 \mathrm{~g}$ (Büyükoba) $(p<0.05)$. The highest total phenol content (163.8 mg GAE/100g) was found in Büyükova walnut oil extracted from the Soxhlet system. The total phenol contents of oil samples extracted by the Soxhlet apparatus were observed to be high, which might be due to the presence of more bioactive components. While the antioxidant activity values of walnut oils obtained by cold-press varied between $17.3 \%$ (Kaman-2) and 19.7\% (Kaman-5), the antioxidant activity values of walnut kernel oils extracted using the Soxhlet apparatus were between $18.4 \%$ (Kaman-2) and $23.8 \%$ (Büyükoba). The antioxidant activity values of oil samples increased in parallel with the total phenol. Abe et $a l .{ }^{20)}$ reported that walnut kernels contained $2499 \mathrm{mg}$ GAE/100g of total phenol and $120 \mu \mathrm{mol}$ Troloxeq/g(fw) of antioxidant capacity. The results showed some differences compared to literature values ${ }^{1,2,7,19,20)}$. The quality properties of walnut oils changed depending on the genotype and climatic conditions and maturity ${ }^{21-23)}$.

Fatty acid compositions of walnut oils extracted in both cold-press and Soxhlet extraction systems are presented in Table 2. The fatty acid compositions of oils changed depending on the walnut varieties and extraction types. The most abundant fatty acids of walnut oils obtained in cold press and Soxhlet apparatus were linoleic acid, followed by oleic and linolenic acids. The palmitic acid contents of walnut oils obtained in from cold-press varied between

Table 1 Physico-chemical and bioactive properties of walnut oils obtained by cold press and Soxhlet extraction.

\begin{tabular}{|c|c|c|c|c|c|c|}
\hline & \multicolumn{3}{|c|}{ Cold press } & \multicolumn{3}{|c|}{ Soxhlet extraction } \\
\hline Parameters & Kaman-2 & Kaman-5 & Büyükoba & Kaman-2 & Kaman-5 & Büyükoba \\
\hline Acid value $(\mathrm{mgKOH} / \mathrm{g})$ & $0.48 \pm 0.03_{* a}$ & $0.41 \pm 0.05_{\mathrm{b}}$ & $0.37 \pm 0.09 \mathrm{a}$ & $0.51 \pm 0.07_{\mathrm{b}}$ & $0.54 \pm 0.01_{\mathrm{a}}$ & $0.45 \pm 0.09 \mathrm{c}$ \\
\hline Peroxide value $\left(\right.$ meq $\mathrm{O}_{2} / \mathrm{kg}$ ) & $2.27 \pm 0.21_{\mathrm{b}^{* *}}$ & $2.68 \pm 0.13_{\mathrm{a}}$ & $1.89 \pm 0.19_{\mathrm{c}}$ & $2.51 \pm 0.27 \mathrm{~b}$ & $2.87 \pm 0.18_{\mathrm{a}}$ & $2.09 \pm 0.15_{\mathrm{c}}$ \\
\hline Saponification value $(\mathrm{mg} \mathrm{KOH} / \mathrm{g})$ & $104.60 \pm 1.17_{\mathrm{c}}$ & $109.90 \pm 1.23_{\mathrm{a}}$ & $106.80 \pm 1.24_{b}$ & $103.90 \pm 1.32_{\mathrm{c}}$ & $108.20 \pm 1.45_{\mathrm{a}}$ & $105.92 \pm 1.52_{\mathrm{b}}$ \\
\hline Density $\left(\mathrm{g} / \mathrm{cm}^{3} ; 25^{\circ} \mathrm{C}\right)$ & $0.927 \pm 0.013_{\mathrm{b}}$ & $0.938 \pm 0.021_{\mathrm{a}}$ & $0.917 \pm 0.017_{\mathrm{c}}$ & $0.951 \pm 0.011_{\mathrm{c}}$ & $0.962 \pm 0.009_{\mathrm{a}}$ & $0.959 \pm 0.015_{b}$ \\
\hline Unsaponifiable value (\%) & $0.48 \pm 0.03_{\mathrm{a}}$ & $0.41 \pm 0.07_{\mathrm{c}}$ & $0.43 \pm 0.01_{b}$ & $0.87 \pm 0.09_{\mathrm{c}}$ & $0.93 \pm 0.07_{\mathrm{a}}$ & $0.89 \pm 0.06_{b}$ \\
\hline Iodine value $\left(\mathrm{gI}_{2} / 100 \mathrm{~g}\right.$ oil $)$ & $130.10 \pm 1.53_{\mathrm{b}}$ & $137.30 \pm 1.62_{\mathrm{a}}$ & $129.60 \pm 1.49_{\mathrm{c}}$ & $128.30 \pm 1.61_{b}$ & $131.60 \pm 1.47_{\mathrm{a}}$ & $128.0 \pm 1.64_{b}$ \\
\hline Refractive Index $\left(\mathrm{n}^{20}{ }_{\mathrm{D}}\right)$ & $1.542 \pm 0.009_{b}$ & $1.547 \pm 0.007_{\mathrm{b}}$ & $1.549 \pm 0.003_{\mathrm{a}}$ & $1.539 \pm 0.011_{\mathrm{a}}$ & $1.531 \pm 0.005_{\mathrm{c}}$ & $1.538 \pm 0.003_{b}$ \\
\hline Total pheno $1(\mathrm{mgGAE} / 100 \mathrm{~g})$ & $121.90 \pm 2.34_{c}$ & $138.70 \pm 1.67_{b}$ & $154.60 \pm 3.42_{\mathrm{a}}$ & $135.90 \pm 3.67_{\mathrm{c}}$ & $147.10 \pm 1.78_{\mathrm{b}}$ & $163.80 \pm 3.86_{a}$ \\
\hline Antioxidant activity (\%) & $17.30 \pm 1.17_{\mathrm{c}}$ & $19.70 \pm 1.24_{\mathrm{a}}$ & $18.50 \pm 1.13_{\mathrm{b}}$ & $18.40 \pm 1.08_{\mathrm{c}}$ & $21.60 \pm 1.12_{b}$ & $23.80 \pm 2.34_{a}$ \\
\hline
\end{tabular}

$*_{\text {mean }} \pm$ standard deviation; $* *$ Values within each row followed by different letters are significantly different $(p<0.05)$. 


\section{A. M. Ahmed, F. Y. A.-Juhaimi, M. M. Özcan et al.}

Table 2 Fatty acid compositions of walnut oils obtained by cold press and Soxhlet extraction (\%).

\begin{tabular}{lcccccc}
\hline & \multicolumn{3}{c}{ Cold press } & \multicolumn{3}{c}{ Soxhlet extraction } \\
\hline Fatty acids & Kaman-2 & Kaman- 5 & Büyükoba & Kaman-2 & Kaman- 5 & Büyükoba \\
\hline Myristic & $0.06 \pm 0.01_{*_{\mathrm{a}}}$ & $0.05 \pm 0.01_{\mathrm{b}}$ & $0.04 \pm 0.01_{\mathrm{c}}$ & $0.03 \pm 0.01_{\mathrm{b}}$ & $0.04 \pm 0.01_{\mathrm{a}}$ & $0.02 \pm 0.00_{\mathrm{c}}$ \\
Palmitic & $6.81 \pm 0.32_{\mathrm{a}^{* *}}$ & $6.67 \pm 0.18_{\mathrm{b}}$ & $6.28 \pm 0.09_{\mathrm{c}}$ & $6.58 \pm 0.17_{\mathrm{a}}$ & $6.55 \pm 0.21_{\mathrm{b}}$ & $6.51 \pm 0.13_{\mathrm{b}}$ \\
Palmitoleic & $0.14 \pm 0.03_{\mathrm{b}}$ & $0.16 \pm 0.01_{\mathrm{a}}$ & $0.16 \pm 0.03_{\mathrm{a}}$ & $0.11 \pm 0.01_{\mathrm{c}}$ & $0.12 \pm 0.01_{\mathrm{b}}$ & $0.13 \pm 0.03_{\mathrm{a}}$ \\
Stearic & $2.83 \pm 0.17_{\mathrm{b}}$ & $2.87 \pm 0.32_{\mathrm{a}}$ & $2.64 \pm 0.24_{\mathrm{c}}$ & $2.91 \pm 0.21_{\mathrm{b}}$ & $2.95 \pm 0.19_{\mathrm{a}}$ & $2.88 \pm 0.13_{\mathrm{c}}$ \\
Oleic & $20.64 \pm 0.56_{\mathrm{c}}$ & $25.89 \pm 0.61_{\mathrm{a}}$ & $23.55 \pm 0.39_{\mathrm{b}}$ & $19.71 \pm 0.57_{\mathrm{c}}$ & $24.93 \pm 0.28_{\mathrm{a}}$ & $22.78 \pm 0.55_{\mathrm{b}}$ \\
Linoleic & $56.71 \pm 0.89_{\mathrm{a}}$ & $55.19 \pm 0.54_{\mathrm{b}}$ & $56.48 \pm 0.28_{\mathrm{a}}$ & $54.47 \pm 0.64_{\mathrm{b}}$ & $54.88 \pm 0.48_{\mathrm{b}}$ & $55.93 \pm 0.51_{\mathrm{a}}$ \\
Linolenic & $15.79 \pm 0.13_{\mathrm{a}}$ & $15.23 \pm 0.17_{\mathrm{a}}$ & $16.48 \pm 0.63_{\mathrm{b}}$ & $14.63 \pm 0.41_{\mathrm{b}}$ & $14.98 \pm 0.57_{\mathrm{b}}$ & $15.77 \pm 0.13_{\mathrm{a}}$ \\
Eicosenoic & $0.15 \pm 0.03_{\mathrm{b}}$ & $0.14 \pm 0.01_{\mathrm{c}}$ & $0.16 \pm 0.05_{\mathrm{a}}$ & $0.18 \pm 0.02_{\mathrm{a}}$ & $0.16 \pm 0.03_{\mathrm{c}}$ & $0.17 \pm 0.01_{\mathrm{b}}$ \\
\hline
\end{tabular}

${ }^{*}$ mean \pm standard deviation;** Values within each row followed by different letters are significantly different $(p<0.05)$.

6.28\% (Büyükoba) and $6.81 \%$ (Kaman-2), and that obtained in Soxhlet apparatus ranged between $6.51 \%$ (Büyükoba) and 6.58\% (Kaman-2). Stearic acid contents of walnut oils obtained through cold-press were between 2.64 (Büyükoba) and $2.87 \%$ (Kaman-5), while that obtained from Soxhlet extraction system ranged between $2.88 \%$ (Büyükoba) and 2.95\% (Kaman-5). The oleic acid contents of oil samples obtained from cold-press were determined between $20.64 \%$ (Kaman-2) and 25.89\% (Kaman-5), while that extracted in Soxhlet extraction system ranged between $19.71 \%$ (Kaman-2) and 24.93\% (Kaman-5) $(p<$ $0.05)$. Linoleic acid contents of oil samples extracted through cold-press method varied between 55.19\% (Kaman-5) and $56.71 \%$ (Kaman-2), while that extracted through Soxhlet extraction system varied between 54.47\% (Kaman-2) and 55.93\% (Büyükoba). The highest linoleic acids were found in Kaman-2 and Büyükoba walnut oils (56.71 and 55.93\%) extracted in cold press and Soxhlet extraction systems, respectively. Linolenic acid contents of walnut oils obtained from cold-press were between 15.23\% (Kaman-5) and 16.48\% (Büyükoba), while that oils extracted through Soxhlet extraction varied between 14.63\% (Kaman-2) and 15.77\% (Büyükoba). As the impurities in the oils obtained from the Soxhlet Soxhlet system were probably higher, linoleic and linolenic acid contents were higher in the cold-pressed oils. The highest content of eicosenoic acid $(0.18 \%)$ was found in Kaman-2 walnut oil extracted in Soxhlet apparatus $(p<0.05)$. Significant differences were observed among the fatty acid compositions of walnut oil samples extracted through cold-press and Soxhlet apparatus. However, palmitoleic and linolenic acid contents of Kaman 5 to Büyükoba and Kaman 2 to Kaman 5 walnut oils (respectively) obtained in cold press were found to be statistically similar. In addition, linoleic and linolenic acid contents of Kaman 2 and Kaman 5, and palmitic acid contents of Kaman 5 and Büyükoba walnut oils obtained by Soxhlet extraction were found to be statistically similar. Fatty acids showed some differences depending on walnut types and extraction methods. Some of these differences were owing to the extraction method used $(p<0.05)$.
Generally, fatty acids of walnut oils obtained from the coldpress system were found to be higher than the oil obtained by the Soxhlet extraction system. Özcan et al. ${ }^{2)}$ reported that walnut oil contained $6.3-6.5 \%$ palmitic, $2.5-2.6 \%$ stearic, $20.5-26.4 \%$ oleic, $49.7-55.5 \%$ linoleic and $14.5-$ $14.8 \%$ linolenic acids. Özkan and Koyuncu ${ }^{1)}$ reported that the main fatty acids of walnut genotype oils were 5.24$7.62 \%$ palmitic, $2.56-3.67 \%$ stearic, $21.18-40.20 \%$ oleic, 43.94-60.12\% linoleic, and 6.91-11.52\% linolenic acids. Kırbaşlar et al ${ }^{19)}$ determined $0.04 \%$ myristic, $7.18 \%$ palmitic, $3.07 \%$ stearic, $13.55 \%$ oleic, $63.42 \%$ linoleic, and $12.22 \%$ linolenic acids in walnut oil extracted using the Soxhlet apparatus. In another study, walnut oil contained $6.46 \%$ palmitic, $2.65 \%$ stearic, $15.61 \%$ oleic, $64.14 \%$ linoleic, and $10.77 \%$ linolenic acids ${ }^{7}$. Bujdoso et al. ${ }^{24)}$ reported that the oil of some walnut cultivars contained 6.09$7.14 \%$ palmitic, $1.94-2.90 \%$ stearic, $16.18-30.14 \%$ oleic, $50.10-62.66 \%$ linoleic, and $8.35-14.19 \%$ linolenic acids. In another study, the minimum and maximum values of polyunsaturated fatty acids linoleic acid and $\alpha$-linolenic acids in walnut oils were found to be $53.24 \%$ to $64.56 \%$ and $9.50 \%$ to $13.26 \%$, respectively ${ }^{25)}$. Mereles et al. $^{26)}$ determined 0.2 $18.4 \mathrm{mg} / 100 \mathrm{~g} \alpha$-tocopherol, 7.01-12.80\% palmitic, 3.47$5.64 \%$ stearic, and 33.90-46.61\% oleic acids in of Macadamia integrifolia nuts cultivated in Paraguay. These results are consistent with those reported by Bujdoso et al. ${ }^{24)}$ and Kurbaşlar et al. ${ }^{19)}$, Özkan and Koyuncu ${ }^{1)}$, Özcan et $a l .{ }^{2)}$, Kafkas et $a{ }^{25}{ }^{25}$ and Mereles et $a l^{26)}$.

The tocopherol contents of walnut oils extracted using cold-press and Soxhlet extraction systems are presented in Table 3. All the tested walnut variety oils are rich in $\alpha$-and $\gamma$-tocopherols. While $\alpha$-tocopherol contents of oil samples obtained using the cold-press system ranged between 4.75 $\mathrm{mg} / 100 \mathrm{~g}$ (Büyükoba) and $5.17 \mathrm{mg} / 100 \mathrm{~g}$ (Kaman-2), the $\alpha$-tocopherol contents of walnut oils extracted through Soxhlet apparatus varied between $4.27 \mathrm{mg} / 100 \mathrm{~g}$ (Büyükoba) and $4.64 \mathrm{mg} / 100 \mathrm{~g}($ Kaman- 2$)(p<0.05)$. The $\gamma$-tocopherol contents of walnut oils extracted in cold-press ranged between $9.41 \mathrm{mg} / 100 \mathrm{~g}$ (Büyükoba) and 10.83 $\mathrm{mg} / 100 \mathrm{~g}$ (Kaman-2), while that obtained from Soxhlet ex- 
Effects of Cold-Press and Soxhlet Extraction Systems on Bioactive Properties of Walnut Kernel Oils

Table 3 Tocopherol contents of walnut oils obtained by cold press and Soxhlet extraction $(\mathrm{mg} / 100 \mathrm{~g})$.

\begin{tabular}{lcccccc}
\hline & \multicolumn{3}{c}{ Cold press } & \multicolumn{3}{c}{ Soxhlet extraction } \\
\hline Tocopherols & Kaman-2 & Kaman- 5 & Büyükoba & Kaman-2 & Kaman- 5 & Büyükoba \\
\hline$\alpha$-tocopherol & $5.17 \pm 0.28_{*_{\mathrm{a}}}$ & $4.98 \pm 0.17_{\mathrm{b}}$ & $4.75 \pm 0.41_{\mathrm{b}}$ & $4.64 \pm 0.38_{\mathrm{a}}$ & $4.31 \pm 0.23_{\mathrm{b}}$ & $4.27 \pm 0.15_{\mathrm{c}}$ \\
$\beta$-tocopherol & $0.34 \pm 0.03_{\mathrm{a}^{* *}}$ & $0.29 \pm 0.05_{\mathrm{c}}$ & $0.31 \pm 0.07_{\mathrm{b}}$ & $0.19 \pm 0.03_{\mathrm{c}}$ & $0.21 \pm 0.01_{\mathrm{b}}$ & $0.24 \pm 0.07_{\mathrm{a}}$ \\
$\gamma$-tocopherol & $10.83 \pm 0.35_{\mathrm{a}}$ & $9.67 \pm 0.28_{\mathrm{b}}$ & $9.41 \pm 0.17_{\mathrm{b}}$ & $9.33 \pm 0.25_{\mathrm{a}}$ & $8.76 \pm 0.31_{\mathrm{b}}$ & $9.13 \pm 0.11_{\mathrm{a}}$ \\
$\delta$-tocopherol & $0.83 \pm 0.09_{\mathrm{b}}$ & $0.87 \pm 0.11_{\mathrm{a}}$ & $0.79 \pm 0.03_{\mathrm{c}}$ & $0.81 \pm 0.07_{\mathrm{b}}$ & $0.83 \pm 0.05_{\mathrm{a}}$ & $0.72 \pm 0.03_{\mathrm{c}}$ \\
\hline
\end{tabular}

*mean \pm standard deviation;** Values within each row followed by different letters are significantly different $(p<0.05)$.

traction varied between $8.76 \mathrm{mg} / 100 \mathrm{~g}($ Kaman-5) and 9.33 $\mathrm{mg} / 100 \mathrm{~g}($ Kaman-2). The highest $\beta$-tocopherol and $\delta$-tocopherol contents were determined in Kaman-2 $(0.34$ $\mathrm{mg} / 100 \mathrm{~g})$ and Kaman-5 $(0.87 \mathrm{mg} / 100 \mathrm{~g})$ obtained from coldpress $(p<0.05)$. Tocopherol contents were higher in the cold-pressed oils because of the probable higher impurities in the oils obtained fromthe Soxhlet system. Significant differences were observed among the tocopherols of walnut oil samples extracted in cold-press and Soxhlet extraction systems $(p<0.05)$. However, $\alpha$-tocopherol and $\gamma$-tocopherol contents of Kaman 5 to Büyükoba walnut oils obtained by cold-press were found to be statistically similar. Uzunova et $a l .{ }^{7}$ reported that walnut oils contained 4.4-5.7\% $\alpha$-tocopherol, 0.0-0.2\% $\beta$-tocopherol, 85.1$88.2 \% \gamma$-tocopherol, and $6.1-9.7 \% \delta$-tocopherol. Kornsteiner et al. ${ }^{21)}$ determined $12.4-32.8 \% \mathrm{mg} / 100 \mathrm{~g} \beta$ - and $\gamma$-tocopherol and 2.3-5.4 mg/100g $\delta$-tocopherols in walnut oils. Kafkas et $a l .{ }^{25)}$ reported that tocopherol and its isomers such as $\alpha, \gamma+\beta$, and $\delta$ tocopherol content of experimental walnut varieties were different. $\alpha$-Tocopherol content of cultivars varied between $28.33 \mu \mathrm{g} / \mathrm{g}$ (Howard) and $38.76 \mu \mathrm{g} /$ $\mathrm{g}$ (Sen), $\beta+\gamma$ tocopherol content varied between 161.01 $\mu \mathrm{g} / \mathrm{g}$ (Howard) to $312.19 \mu \mathrm{g} / \mathrm{g}$ (Sen) and as for the $\delta$-tocopherol content varied between $17.35 \mu \mathrm{g} / \mathrm{g}$ (Serr) to $40.77 \mu \mathrm{g} / \mathrm{g}(\mathrm{Sen}) \mathrm{oil}^{25)}$. Mereles et $a l^{26)}$ determined 0.2-18.4 $\mathrm{mg} / 100 \mathrm{~g} \alpha$-tocopherol in three cultivars of Macadamia integrifolia nuts cultivated in Paraguay. In a previous study, the tocopherol compositions analyzed by using highperformance liquid chromatography have shown that $\alpha$ and $\gamma$-tocopherols were the predominant tocopherol homo$\operatorname{logs}$ present; however, $\delta$ - and $\beta$-tocopherols were also detected in some samples ${ }^{28)}$. In another study, Lavedrine et $a l .{ }^{29)}$ studied two walnut varieties (Franquette and Hartley) from two geographical origins (France, and USA), and the amounts of $\alpha, \gamma$, and $\delta$ tocopherols of walnut oils ranged from 1.08 to 4.05 , from 21.78 to 26.46 , and from 2.51 to $4.23(\mathrm{mg} / 100 \mathrm{~g})$, respectively. Also, Bada et al. ${ }^{30)}$ reported that $\gamma$-tocopherol was the major component of the total tocopherols in the walnut sample under study (from $289.01 \pm$ $6.02-76.52 \pm 5.98 \mathrm{mg} / \mathrm{kg}$ oil). In addition, Oliveira et $a l^{31}{ }^{31}$ determined 303.2 and $405.7 \mu \mathrm{g} / \mathrm{g}$ of total tocopherol in walnut oil. Maguire et al. ${ }^{32)}$ reported that $\alpha$-tocopherol was the most prevalent tocopherol except in walnuts. These results were somewhat different from those reported by
Uzunova et $a l .{ }^{7)}$, Kafkat et $a l .{ }^{25)}$, Mereles et $a l .{ }^{26)}$, Kornsteiner $e t a l .{ }^{27)}$, Lavedrine $e t a l .{ }^{29)}$, Bada et $a l^{30)}$, Oliveira et $a l .{ }^{31)}$ and Maguire $e t a l .{ }^{32)}$

\section{CONCLUSIONS}

While the acid value, peroxide value, density, and unsaponifiable matter values of oil samples obtained in coldpress increased compared to the results of oils extracted in Soxhlet apparatus, the saponification value, iodine value, and refractive index decreased. The total phenol contents and antioxidant activity values of walnut oils extracted in cold-press were found to be lowerthan the values obtained using the Soxhlet apparatus. The linoleic acid was the dominant fatty acid of walnut oils obtained from both coldpress and Soxhlet extraction systems. The oil samples obtained from cold-press had higher contents of fatty acids and tocopherol contents than those extracted from Soxhlet apparatus, probably because of the presence of more impurities in the oil extracted from the Soxhlet apparatus method. The most abundant fatty acid present in both cold-press and solvent extraction oils was linoleic acid, followed by oleic and linolenic acids. In addition, the coldpressing technique excludes theuse of organic solvents which can yield an oil product free from chemical contaminants such as those used in Soxhlet technique. Walnuts oils enhance the nutritional value of the human diet because of its beneficial properties. The composition of walnut oil can change depending on the fruit variety, origin place, harvest year, and agro-technical measures.

\section{Acknowledgements}

The authors extend their appreciation to the Deanship of Scientific Research at King Saud University for funding this work through research group no. RG-1439-80. Technical support of RSSU at King Saud University is also well appreciated. 


\section{References}

1) Özkan, G.; Koyuncu, M.A. Physical and chemical comparision of some walnut (Juglans regia L.) genotypes grown in Turkey. Grasas y Aceites 56, 142-147(2005).

2) Özcan, M.M.; İman, C.; Arslan, D. Physico-chemical properties, fatty acid and mineral content of some walnuts (Juglans regia L.) types. Agric. Sci. 1, 62-67 (2010).

3) Simopoulos, A.P. The Mediterranean diets: what is so special about the diet of Greece? The scientific evidence. J. Nutrition 131, 3065-3073 (2001).

4) Tsamouris, G.; Hatzaintoniou, S.; Demetzos, C. Lipid analysis of Greek walnut oil(Juglans regia L.). Z. Naturforsch. 57, 51-56(2002).

5) Rabrenovic, B.; Dimic, E.; Maksimovic, M.; Sobajic, S.; Gajic-Krstajic, L. Determination of fatty acid and tocopherol composition and the oxidative stability of walnut (Juglans regia L.) cultivars grown in Serbia. Czech J. Food Sci. 29, 74-78(2011).

6) Yerlikaya, C.; Yücel, S.; Korukluoğlu, M. Proximate composition, minerals and fatty acid composition of Juglans regia L. Genotypes and cultivar grown in Turkey. Braz. Arch. Biol. Technol. 55, 677-683 (2012).

7) Uzunova, G.; Perifanova-Nemska, M.; Stojanova, M.; Gandev, St. Chemical composition of walnut oil from fruits on different years old branches. Bulgarian J. Agric. Sci. 21, 494-497(2015).

8) Savage, G.P.; Dutta, P.C.; McNeil, D.L. Fatty acid and tocopherol contents and oxidative stability of walnut oils. J. Agric. Food Chem. 9, 1059-1063 (1999).

9) Özcan, M.M.; Rosa, A.; Dessi, M.; Marongiu, B.; Piras, A., AlJuhaimi, F. Quality of wheat germ oil obtained by cold pressing and supercritical carbon dioxide extraction. Czech J. Food Sci. 31, 236-240 (2013).

10) Goldberg, G. Plants: Diet and Health. The Report of a British Nutrition Foundation Task Force. Blackwell Science, Oxford, U.K(2003).

11) Rotkiewicz, D.; Konopka, I.; Zylik, S. State of works on the rapeseed oil processing optimalization. I. Oil obtaining. Ros' liny Oleiste/ Oilseed Crops XX, pp. 151168(1999).

12) AOAC. Official Methods of Analysis, 15th ed. Association of Official Analytical Chemists, Washington, DC (1990).

13) Talhaoui, N.; Gomez-Caravana, A.M.; Leon, L.; De la Rosa, R.; Segura-Carretero, A.; Fernandez-Gutierrez, A. Determination of phenolic compounds of 'Sikitita' olive leaves by HPLC-DAD-TOF-Ms. Comparison with its parents 'Arbequina' and 'Picual' olive leaves. LWT-Food Sci. Technol. 58, 28-34(2014).

14) Yoo, K.M.; Lee, K.W.; Park,J.B.; Lee, H.J.; Hwang, I.K. Variation in major antioxidants and total antioxidant activity of Yuzu(Citrusjunos siebex Tanaka)during maturation and between cultivars. J. Agric. Food Chem. 52, 5907-5913(2004).

15) Lee, S.K.; Mbwambo, Z.H.; Chung, H.S.; Luyengi, L.; Games, E.J.C.; Mehta, R.G. Evaluation of the antioxidant potential of natural products. Comb. Chem. High Throughput Screen. 1, 35-46 (1998).

16) ISO-International Organization for Standardization. Animal and vegetable fats and oils preperation of methyl esters of fatty acids, ISO. Geneve, Method ISO 5509, pp. 1-6 (1978).

17) Spika, M.J.; Kraljic, K.,; Koprivnjak, O.; Skevin, D.; Zanetic, M.; Katalinic, M. Effect of agronomical factors and storage conditions on the tocopherol content of Oblica and Leccino virgin olive oil. J. Am. Oil Soc. 92, 1293-1301 (2015).

18) Püskülcü, H.; İkiz, F. Introduction to Statistic. Bilgehan Press. Bornova, İzmir, Turkey p. 333(1989). (in Turkish).

19) Kırbaşlar, F.G.; Türker, G.; Özsoy-Güneş, Z.; Ünal, M.; Dülger, B.; Ertaş, E.; Kızılkaya, B. Evaluation of fatty acid composition, antioxidant and antimicrobial activity, mineral composition and calories values of some nuts and seeds from Turkey. Rec. Nat. Prod. 6, 339349 (2012).

20) Abe, L.T.; Lajolo, F.M.; Genovese, M.I. Comparison of phenol content and antioxidant capacity of nuts. Cienc. Technol. Aliment. Camp. 30, 254-259 (2010).

21) Ünver, H.; Sakar, E.; Sülüşoğlu, M. Determination of pomological and morphological characteristics with fatty acid composition of high kernel ratio walnut genotypes. Erwerbs-Obstbau 58, 11-18(2016).

22) Yılmaz, S.; Akça, Y. Determination of biochemical properties and fatty acid composition of new walnut (Juglans regia) genotypes. J. Agric. Fac. Gaziosmanpasa Univ. 34, 74-80 (2017).

23) Matthäus, B.; Özcan, M.M.; Al Juhaimi, F.; Adiamo, O.Q.; Alsawmahi, O.N.; Ghafoor, K.; Babiker, E.E. Effect of the harvest time on oil yield, fatty acid, tocopherol and sterol contents of developing almond and walnut kernels. J. Oleo Sci. 67, 39-45(2018).

24) Bujdoso, G.; Konya, E.; Berki, M.; Nagy-Gasztonyi, M.; Bartha-Szügyi, K.; Marton, B.; Izsepi, F.; Adanyi, N. Fatty acid composition, oxidative stability, and antioxidant properties of some Hungarian and other Persian walnut cultivars. Turk. J. Agric. For. 40, 160-168 (2016).

25) Kafkas, E.; Burgut, A.; Ozcan, H.; Ozcan, A.; Sutyemez,M.; Kafkas, S.;Türemis, N. Fatty acid, total phenol and tocopherol profiles of some walnut cultivars: A comparative study. Food Nutri. Sci. 8, 10741084 (2017).

26) Mereles, L.G.; Ferro, E.A.; Alvarenga, N.L.; Caballero, S.B.; Wiszovaty, L.N.; Piris, P.A.; Michajluk, B.J. Chemical composition of Macadamia integrifolia (Maiden 
and Betche)nuts from Paraguay. Int. Food Res. J. 24, 2599-2608(2017).

27) Kornsteiner, M.; Wagner, K.H.; Elmadfa, I. Tocopherols and total phenolics in 10 different nut types. Food Chem. 98, 381-387 (2006).

28) Mirakliakbari, H.; Shahidi, F. Lipid class compositions, tocopherol and sterols of tree nut oils extracted with different solvents. J. Food Lipids 15, 81-96 (2008).

29) Lavedrine, F.; Ravel, A.; Poupard, A.; J.Alary, J. Effect of geographic origin, variety and storage on tocopherol concentrations in walnuts by HPLC. Food Chem. 58, 135-140 (1997).

30) Bada, J.C.; León-Camacho, M.; Prieto, M.; Copovi, P.;
Alonso, L. Characterization of Walnut Oils (Juglans regia L.) from Asturias, Spain. J. Am. Oil Chem. Soc. 87, 1469-1474(2010).

31) Oliveira, R.; Fátima Rodrigues, M.; Gabriela BernardoGil, M. Characterization and supercritical carbondioxide extraction of walnut oil. J. Am. Oil Chem. Soc. 79, 225-230 (2002).

32) Maguire, L.S.; O’ Sullivan, S.M.; Galvin, K.; O’ Connor, T.P.; O'Brien, N.M. Fatty acid profile, tocopherol, squalene and phytosterol content of walnuts, almonds, peanuts, hazelnuts and the macadamia nut. Int. J. Food Sci. Nutr. 55, 171-178(2004). 